\title{
Anesthetic Implications of Robotic-Assisted Surgery in Pediatric Patients
}

\author{
Mayuko Wakimoto' \\ Marc Michalsky ${ }^{2}$ \\ Olubukola $\mathrm{Nafiu}^{3}$ \\ Joseph Tobias $\mathbb{D}^{3}$ \\ 'Department of Anesthesiology, Osaka \\ Police Hospital, Osaka, Japan; \\ ${ }^{2}$ Department of Pediatric Surgery, \\ Nationwide Children's Hospital and the \\ Ohio State University College of \\ Medicine, Columbus, OH, USA; \\ ${ }^{3}$ Department of Anesthesiology \& Pain \\ Medicine, Nationwide Children's Hospital \\ and the Ohio State University College of \\ Medicine, Columbus, $\mathrm{OH}$, USA
}

\begin{abstract}
The novel technology of robotic-assisted surgery (RAS) has been utilized in children for the past two decades with several potential clinical benefits including reduction of postoperative pain, shortened hospital length of stay, and improved cosmetic outcomes. While associated costs and the limitations regarding instruments for smaller pediatric patients remain relevant issues, surgeon comfort related to ergonomic design in combination with enhanced three-dimensional high-fidelity imaging and tissue handling compared to traditional minimally invasive approached may offer improved surgical and postoperative outcomes. Given that the demand for this innovative technology will likely continue to expand in the field of pediatric surgery, pediatric anesthesiologists will be called upon to provide anesthetic care to patients exposed to this novel surgical technology with its unique features, intraoperative requirements, and potential complications. The current manuscript provides a narrative review of robotic-assisted surgery and discusses important anesthetic considerations and potential complications of these techniques.
\end{abstract}

Keywords: robotic-assisted surgery, pediatric anesthesiology, minimally invasive surgery

\section{Introduction}

There is an ongoing search for innovative operative techniques that are less invasive, limit physiologic stress, and provide improved clinical outcomes following surgical procedures. Robotic-assisted surgery (RAS) has become a common practice in many specialties and in many institutions among the adult population in response to an increasing demand for increased surgical precision and visualization, fast-track postoperative recovery, and improved cosmetic outcomes. The potential benefits of RAS in adults have included smaller surgical incisions, shorter time to postoperative ambulation, decreased hospital length of stays, improved cosmetic outcomes, and a reduction in postoperative pain. ${ }^{1-4}$ Despite these advantages, RAS generally remains more costly than traditional minimally invasive surgical techniques, including laparoscopy and/or thoracoscopy as well as conventional or "open" surgical procedures. ${ }^{5,6}$ Following the first report of RAS in a pediatric patient in 2002, its applications in children have expanded to include multiple procedures and multiple specialties such as urology, general pediatric surgery, and cardiothoracic surgery for patients from infants to adolescents (Table 1 ). ${ }^{7}$ The rapid increase in its application for children is evident by a dramatic increase of published manuscripts over the past 18-20 years (Figure 1). The number of published manuscripts increased from 3 in 2002 to more than 40 in the 2019. The most common surgical procedures from these publications were urology followed by pediatric surgery. ${ }^{8}$
Correspondence: Mayuko Wakimoto Department of Anesthesiology, Osaka Police Hospital, Osaka, Japan Email wakimoto-knks@umin.ac.jp 
Table I Applications of Robotic-Assisted Surgery in the Pediatric Population

\begin{tabular}{|c|c|c|c|}
\hline Neurological & Cardiothoracic & Gastrointestinal & Genitourinary \\
\hline \multirow[t]{2}{*}{ Third ventriculostomy } & Lobectomy & Fundoplication & Pyeloplasty \\
\hline & Thymectomy & Gastrostomy & Ureteral reimplantation \\
\hline Otolaryngology & Benign mass excision & Cholecystectomy & Ureteroureterostomy \\
\hline Thyroid lobectomy & Tumor related & Splenectomy & Nephrectomy (total/partial) \\
\hline Thyroidectomy & Congenital diaphragmatic hernia repair & $\begin{array}{l}\text { Meckel's } \\
\text { diverticulectomy }\end{array}$ & Mitrofanoff \\
\hline Subtotal parathyroidectomy & Diaphragmatic plication & Rectopexy & Augmentation cystoplasty \\
\hline Dermoid cyst excision & Bronchogenic cyst excision & Esophago-myotomy & $\begin{array}{l}\text { Retrovesical remnant } \\
\text { excision }\end{array}$ \\
\hline Tongue basal reduction & Thoracic sympathectomy & $\begin{array}{l}\text { Choledochal cyst } \\
\text { excision }\end{array}$ & Sigmoid vaginoplasty \\
\hline Laryngeal cleft repair & Segmentectomy & Hiatal hernia repair & Uretero-calicostomy \\
\hline Lingual tonsillectomy & Esophageal fistula repair & Tumor related & Orchidopexy \\
\hline $\begin{array}{l}\text { Posterior glottic stenosis } \\
\text { repair }\end{array}$ & Tracheoesophageal fistula repair & Bariatric surgery & Gonadal vein ligation \\
\hline \multirow[t]{11}{*}{ Tumor resection } & Duplication cyst excision & Kasai procedure & Varicocelectomy \\
\hline & Pleurectomy & Colectomy & Pyeloplasty \\
\hline & Atrial septal defect closure & Adrenalectomy & Cysto-urethropexy \\
\hline & Patent ductus arteriosus closure & Appendectomy & Pyelolithotomy \\
\hline & Mitral valve replacement & Pyloromyotomy & Tumor related \\
\hline & Tricuspid valve annuloplasty & Pyloroplasty & Urachal remnant excision \\
\hline & $\begin{array}{l}\text { Partial anomalous pulmonary venous connection } \\
\text { repair }\end{array}$ & Entero-enterotomy & Nephro-ureterectomy \\
\hline & & Inguinal hernia repair & Renal vascular hitch \\
\hline & & Duodeno-jejunostomy & Hypospadias repair \\
\hline & & Duplication cyst excision & \\
\hline & & Pancreatojejunostomy & \\
\hline
\end{tabular}

Use of the robotic surgical system in pediatric patients may present various unique and challenging features including patient positioning, limited patient access, and physiologic changes induced by requisite $\mathrm{CO}_{2}$ insufflation to improve surgical visualization. Understanding these unique challenges and adjusting the anesthesia technique may be required during RAS. The current manuscript addresses the anesthetic considerations and potential complications of RAS focusing on pediatric patients. This review also includes a brief discussion of the physiologic implications of $\mathrm{CO} 2$ insufflation which remains a prerequisite for both laparoscopic procedures as well as RAS. The authors reviewed relevant literature using PubMed/Medline from 2002-2020 and utilizing a combination of the following terms: "robotic assisted surgery", "pediatric", "anesthesia", "anesthetic", and "complication". Abstracts were screened and animal or adult studies and publications written in languages other than English were excluded. In addition, reference lists of published articles were also examined for additional 


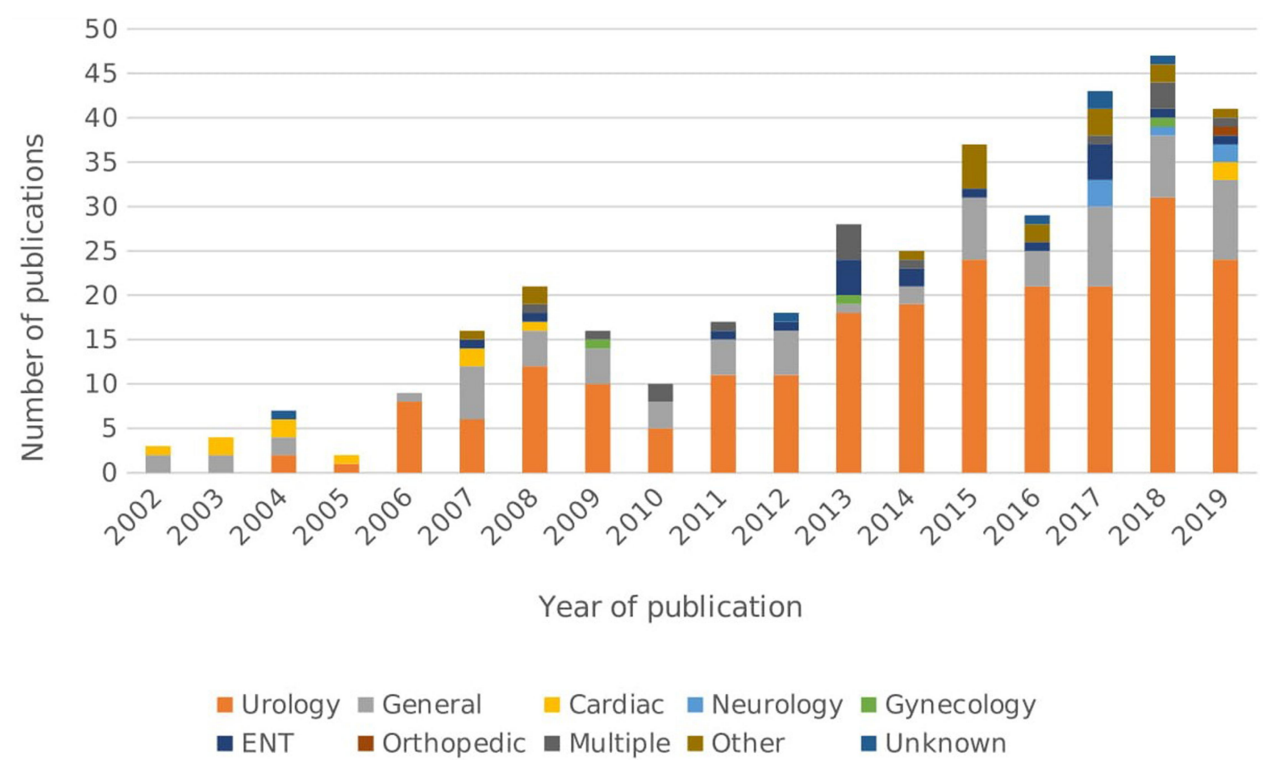

Figure I The number of published manuscripts related to pediatric robotic-assisted surgery over the past 18 years. Each column represents the number of papers published in that year, increasing from 3 in 2002 to more than 40 in the 2019. PubMed was searched using the terms "robotic assisted surgery", "pediatric", "anesthesia", "anesthetic", "complication" between 2002 and 2019. Abstracts were screened and animal or adult studies as well as publications written in languages other than English were excluded. Reference lists of published articles were also examined and added if applicable. "Multiple" includes multiple procedures such as urology and general surgery. Other includes articles focusing on instruments or surgeons learning curve on robotic surgery. Unknown includes article which did not have a specific procedure name on the abstract.

manuscripts which were not identified from the literature searches.

\section{The Robotic System and Specific Considerations for Pediatric Patients}

The United States Food and Drug Administration (FDA) has currently approved only 2 "general purpose" robotic systems for use in adults, the da Vinci Surgical System (Intuitive Surgical Inc, Mountain View, California, USA), and the Senhance Surgical System (TransEnterix, Inc, Research Triangle Park, North Carolina). With 5989 active systems in operation globally as of December 31, 2020, including 3720 in the US alone, the da Vinci Surgical System has dominated the general-purpose clinical market space in the United States and worldwide since being approved by the FDA in 2000. Despite the recent entry of the Senhance System in 2018 and several other competitive platforms currently in use outside the United States, which are in development or pending regulatory approval, the da Vinci systems remains the only robot with FDA approval for pediatric indications.

The da Vinci System is comprised of three separate components: 1) surgeon console, 2) patient cart, and 3) vision cart (Figure 2). The operating surgeon sits at the surgeon console, which houses the controls for a various

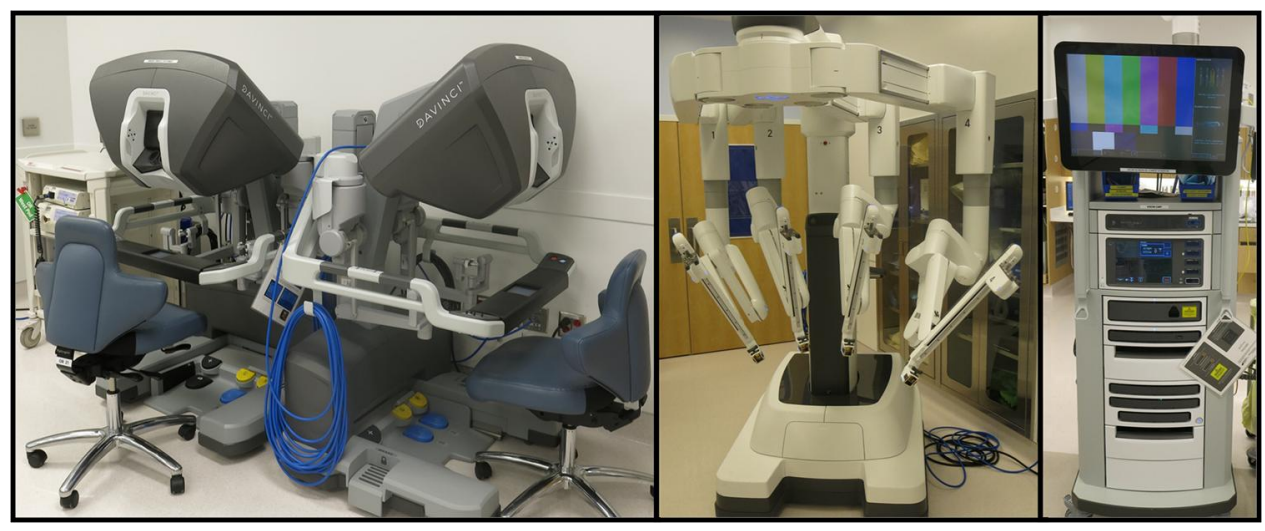

Figure 2 Components of the da Vinci robotic surgery system including the vision cart, patient cart, and surgeon console. 
array of surgical instruments that are attached to the patient cart and subsequently controlled while viewing the patient's anatomy through a high-fidelity threedimensional display. The vision cart serves as a digital communication hub between all components and supports the 3-dimensional (3D) vision system.

The da Vinci Surgical robotic system was initially designed and targeted for adult patients with cardiac surgery, and hence its technology was not universally suited for smaller pediatric patients. For example, the size of the scopes tends to be larger when compared with conventional laparoscopic instruments, especially for infants. Currently available robotic instruments include two endoscopic 3D camera sizes $(12 \mathrm{~mm}$ and $8.5 \mathrm{~mm})$ and two instrument sizes $(5 \mathrm{~mm}$ and $8 \mathrm{~mm})$. The latter include needle-holders, scissors, graspers, cautery instruments, ultrasonic energy instruments, and various other disposable and reusable accessories. ${ }^{7}$ These instruments $(5 \mathrm{~mm}$ and $8 \mathrm{~mm}$ size) are comparatively larger than the $3 \mathrm{~mm}$ instruments that are routinely available and used for laparoscopic procedures in infants and neonates. Due to these differences, the surgical incision length for RAS is larger and comparatively greater than laparoscopic or thoracoscopic techniques. Furthermore, the $8 \mathrm{~mm}$ instruments are generally preferred over the $5 \mathrm{~mm}$ instrumentation as the $5 \mathrm{~mm}$ size lacks bipolar electrocautery, having only monopolar cautery. Additionally, there is restricted wristed-motion of 5-mm instruments as compared with the $8-\mathrm{mm}$ instruments especially when the patient size is small and the space is limited. ${ }^{10,11}$

Another consideration is the recommended distance between the surgical access ports. The manufacturer of the da Vinci Surgical System recommends a $4-8 \mathrm{~cm}$ distance between robotic ports, depending on the specific platform, in order to provide adequate space for movement of the surgical instruments both inside and outside the body cavity. Achieving adequate distance between ports can be challenging for pediatric patients due to the smaller body size and more limited surgical domain. Therefore, thoughtful planning is critical to ensure optimal distance between the ports. $^{7-9}$ Additionally, minor modifications of surgical techniques have been suggested such as allowing a smaller distance of 5-6 $\mathrm{cm}$ between trocar insertion sites as the distance between the ports increases after insufflation. ${ }^{9}$ Given the constraints imposed by the instruments and potential size limitations of the patient, outside of the adolescent and larger pediatric population, the adaptation of RAS remains challenging. This is the case for
Table 2 Benefits and Limitations of Robotic-Assisted Surgery for Pediatric Patients

\begin{tabular}{|l|l|}
\hline Benefits & Limitations \\
\hline $\begin{array}{l}\text { Instruments provide greater } \\
\text { range of motion }\end{array}$ & $\begin{array}{l}\text { The size of the robot requires } \\
\text { sufficient room space and limits } \\
\text { access to the patient }\end{array}$ \\
\hline $\begin{array}{l}\text { Improved visualization with } \\
\text { 3-dimensional camera system }\end{array}$ & $\begin{array}{l}\text { Limited number of the staff who } \\
\text { are familiar with the system }\end{array}$ \\
\hline $\begin{array}{l}\text { Motion scaling and tremor } \\
\text { reduction }\end{array}$ & Room turn-over time \\
\hline $\begin{array}{l}\text { Intuitive movement of the } \\
\text { console }\end{array}$ & Cost \\
\hline $\begin{array}{l}\text { Endo-wrist with } 7^{\circ} \text { of freedom } \\
\text { beyond that of the human wrist } \\
\text { with } 4^{\circ} \text { of freedom }\end{array}$ & $\begin{array}{l}\text { Limited instrument selection for } \\
\text { pediatric patients }\end{array}$ \\
\hline Ergonomic benefit for surgeon & Limitations related to patient size \\
\hline $\begin{array}{l}\text { Lower pain scores and } \\
\text { decreased postoperative opioid } \\
\text { needs }\end{array}$ & $\begin{array}{l}\text { No standardized way to place } \\
\text { trocars }\end{array}$ \\
\hline $\begin{array}{l}\text { Shorter hospital length of stay } \\
\text { Improved cosmetic outcomes }\end{array}$ & $\begin{array}{l}\text { Physiologic effects related to } \\
\text { absorption of carbon dioxide }\end{array}$ \\
\hline
\end{tabular}

pediatric patients that are less than 1 year of age and less than 10 kilograms in weight. The general benefits and limitations of the robotic surgical system are outlined in Table 2.

\section{Intraoperative Considerations}

In recent years, robotic surgery has been utilized in wide variety of procedures including urology, gynecology, gastrointestinal, thoracic, endocrine, and cardiac surgery. The perioperative care may be impacted by the intended surgical procedure, the patient's associated comorbid conditions, and the technique of RAS. The latter includes not only use of the robotic system, but also insufflation of the target body cavity (ie, abdomen or thorax) and its potential impact on physiologic function. Some of the implications of RAS are not specific to the use of the robot itself, but rather a consequence of the use of a minimally invasive technique including the use of $\mathrm{CO} 2$ insufflation within the thorax or abdomen to facilitate surgical visualization.

As with minimally invasive techniques (laparoscopy or thoracoscopy), the preoperative laboratory investigation and 


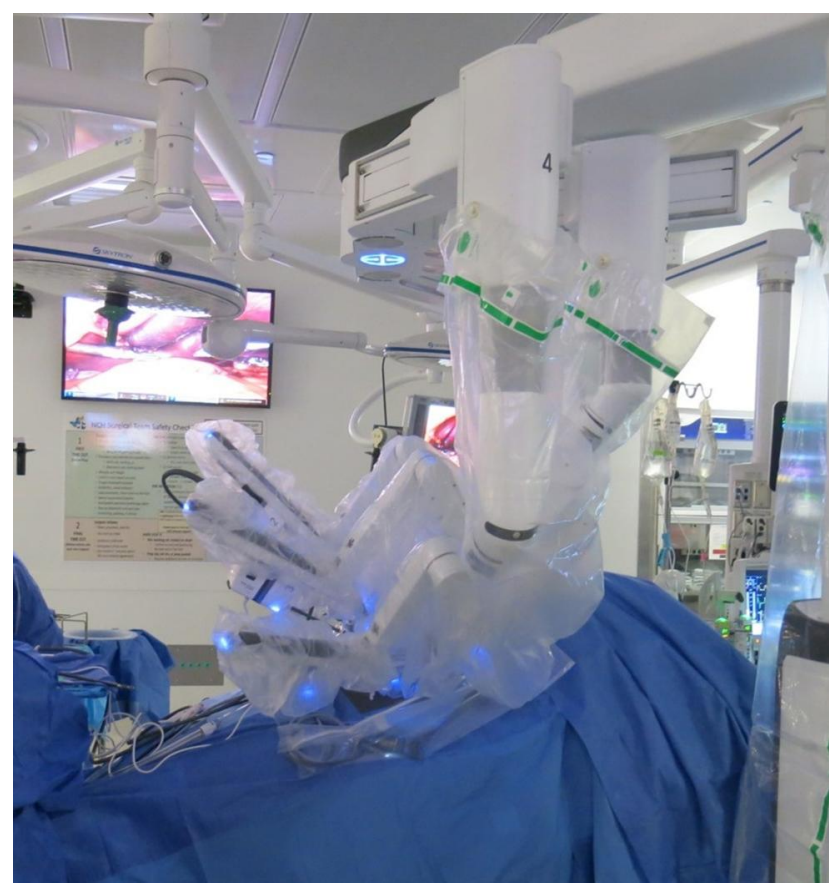

Figure 3 Intraoperative photograph with the robotic surgery system docked at the operating room table which is in reverse Trendelenburg position to facilitate surgical visualization of the abdominal contents. The patient's head is to the right.

work-up is generally guided by the surgical procedure and the patient's comorbid conditions. Given the potential for blood loss and the proximity of major blood vessels, a preoperative hemoglobin value and a type and cross are generally indicated for intrathoracic procedures and those procedures requiring significant intra-abdominal manipulation or resections. Likewise, placement of additional peripheral intravenous cannulas or intraoperative monitoring including the placement of invasive cannulas for monitoring intra-arterial and central venous pressure (CVP) are guided more by the patient's status and the intended surgical procedure rather than the unique implications of RAS. Specific anesthetic considerations for RAS include space issues imposed by the robotic surgical device with limited direct access to the patient, patient positioning, and the physiologic effects of insufflation of a closed cavity (Figure 3). Some of these issues have been improved significantly with the newer da Vinci systems (Xi versus $\mathrm{Si}$ ).

\section{Intra-Abdominal Procedures}

RAS of the abdomen and pelvis requires carbon dioxide (CO2) insufflation into a closed cavity (the peritoneal cavity) to create a pneumoperitoneum and allow effective visualization. In addition, steep Trendelenburg or head-up (reverse Trendelenburg) positioning may be needed to further improve visualization during lower or upper abdominal surgery, respectively. Increased intraabdominal pressure (IAP) and $\mathrm{CO} 2$ absorption during insufflation may impact respiratory and hemodynamic function. The end-organ physiologic effects of laparoscopy have been reviewed elsewhere. ${ }^{10-13}$ Increased IAP during insufflation shifts the diaphragm cephalad, which can potentially result in main stem intubation so ongoing assessment of bilateral breath sounds may be indicated, especially in smaller patients where the distance from the mid-trachea to the mainstem bronchi is limited. The increased IAP also impacts respiratory and cardiovascular function. Respiratory changes include a decreased functional residual capacity, decreased lung compliance, and increased airway resistance. These effects alter ventilation/ perfusion $(\mathrm{V} / \mathrm{Q})$ matching and increase dead space ventilation, which can result in hypoxemia and hypercarbia.

The absorption of the gas used for insufflation and patient positioning may further impact respiratory function. Given its high solubility and limited physiologic impact during inadvertent systemic embolization, carbon dioxide $(\mathrm{CO} 2)$ is universally used for insufflation. Its absorption will cause hypercarbia during the procedure, the magnitude of which is impacted by the duration of the procedure and the IAP. Patient positioning may also affect respiratory function with the Trendelenburg positioning causing cephalad displacement of the diaphragm, generally worsening respiratory function. The reverse Trendelenburg positioning generally unloads the diaphragm and partially mitigates the impact of increased IAP.

Physiological changes are generally manageable with appropriate changes of ventilatory settings including a 20-$25 \%$ increase in minute ventilation to compensate for $\mathrm{CO} 2$ absorption and adjustments in mean airway pressure (positive end expiratory pressure [PEEP], peak inflating pressure [PIP], and inspiratory time) to increase mean airway pressure and compensate for decreased FRC, decreased compliance, and increased resistance. Most importantly, attention to and limitation of the IAP is mandatory. The impact of insufflation on respiratory function is related to the IAP as insufflation pressures less than $10 \mathrm{mmHg}$ will have fewer effects on respiratory function. ${ }^{10-13}$ The use of novel techniques of mechanical ventilation such as volume-guaranteed, pressure-regulated ventilation, may maintain tidal volumes better during periods of changing respiratory resistance and compliance and thereby maintain minute ventilation more effectively than pressure 
or volume-controlled techniques. ${ }^{14}$ In addition to affecting respiratory function, the increased IAP with alterations in dead space and ventilation-perfusion matching may affect end-tidal carbon dioxide monitoring. Although it remains a standard of care for intraoperative monitoring during general anesthesia, end-tidal carbon dioxide (ETCO2) monitoring may be inaccurate during insufflation and alternative continuous techniques such as transcutaneous $\mathrm{CO} 2$ monitoring may offer specific advantages for continuous $\mathrm{CO} 2$ monitoring. ${ }^{15}$

The impact of insufflation on hemodynamic function generally includes a decrease in preload and an increase in afterload. In the adult population, these are manifested by an increase in mean arterial pressure, systemic vascular resistance, left ventricular afterload with a concomitant decrease in cardiac index, stroke volume index, and fractional area shortening with an IAP set at $15 \mathrm{mmHg} .{ }^{16-20} \mathrm{In}$ the pediatric population, the hemodynamic changes vary based on the IAP. Low pressure carbon dioxide pneumoperitoneum (IAP 5-6 $\mathrm{mmHg}$ ) in otherwise healthy children does not impact hemodynamic function. ${ }^{21,22}$ However, with an IAP of $10 \mathrm{mmHg}$, Gueugniaud et al reported that aortic blood flow measured by esophageal Doppler decreased to $67 \pm 9 \%$ of baseline, stroke volume decreased to $68 \pm 10 \%$ of baseline, and systemic vascular resistance increased to $162 \pm 34 \%$ of baseline. ${ }^{23}$ With an IAP greater than $12 \mathrm{mmHg}$, other investigators have demonstrated diminishing left ventricular systolic function using transesophageal echocardiography, with a significant decrease in cardiac index (approximately 10-13\%) from baseline. ${ }^{22,24}$ As with respiratory changes, the hemodynamic changes will be affected by patient positioning as well as hypercarbia due to absorption of $\mathrm{CO} 2$. Hemodynamic effects of hypercarbia include pulmonary vasoconstriction, increased systemic vascular resistance, and arrhythmias. Although these hemodynamic changes are generally well tolerated for a limited period of time in otherwise healthy pediatric patients, the impact may be magnified in patients with pre-existing myocardial function. Despite these concerns, a retrospective database studied confirmed the safety of laparoscopic surgery in infants with CHD including the benefit of a shorterhospital stay. ${ }^{25}$ Insufflation pressures $\leq 10-12 \mathrm{mmHg}$ are generally recommended to limit value its impact on cardiac output and tissue oxygenation.

\section{Intrathoracic Procedures}

Technical challenges, size constraints, and the limited availability of pediatric-appropriate instruments have resulted in a limitation of the reports regarding roboticassisted thoracic surgery in infants and children. To date, these reports have been limited to small series or isolated case reports for treatment of congenital diaphragmatic hernia, esophageal atresia, mediastinal cysts, diaphragmatic hernia, pulmonary lobectomy, esophageal cysts, and patent ductus arteriosus. ${ }^{26-30}$ Given size constraints and limited surgical access, one-lung ventilation (OLV) techniques may be required to allow surgical visualization. $^{31-33}$ Depending on the patient's age and weight, several options are available including a doublelumen ETT, bronchial blocker, and main stem endotracheal intubation. The techniques for and intraoperative anesthetic care during OLV have been reviewed elsewhere. ${ }^{31-33}$ Given technical challenges of OLV in neonates and infants, $\mathrm{CO} 2$ insufflation into the intrapleural cavity with standard two-lung ventilation is an additional option although this may result in systemic hypercarbia related to systemic absorption of $\mathrm{CO} 2$ (see above) as well as hemodynamic effects from the shift of intrathoracic

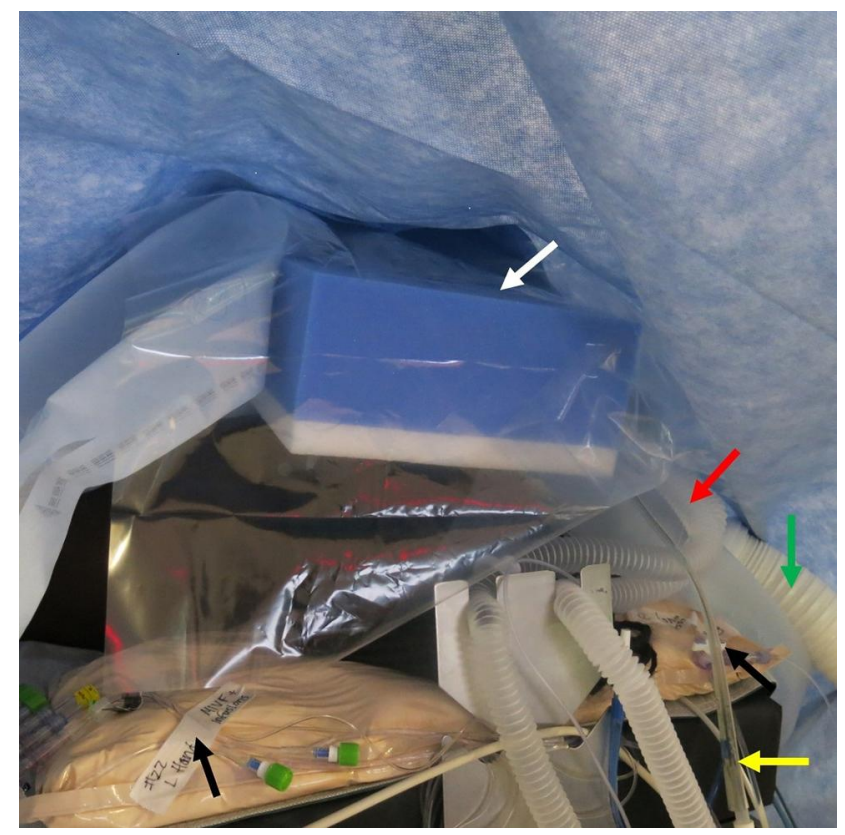

Figure 4 Intraoperative photograph showing the head of the bed. The patient's head is covered with a foam pillow (white arrow) to prevent pressure from any of the surgical instruments or operating personnel. The anesthesia circuit (red arrow); orogastric tube (yellow arrow); Bair hugger tubing (green arrow); and peripheral intravenous infusions (black arrow) are labelled. The patient's head is covered in plastic and an upper body Bair Hugger ${ }^{\mathrm{TM}}$ is placed to maintain normothermia. 
structures. $^{34-37}$ Procedures are generally performed with two instrument arms, one camera arm, and occasionally an additional 5-mm non-robotic accessory port. Carbon dioxide $\left(\mathrm{CO}_{2}\right)$ is used for insufflation at low flow rates and maintained at the lowest possible pressure throughout the procedure. Physiologic implications of $\mathrm{CO} 2$ insufflation include the potential for inadvertent gas embolism, systematic $\mathrm{CO} 2$ absorption across the pleura or peritoneum, and the increase in intrathoracic or intra-abdominal pressure.

\section{Patient Positioning and Limited Access}

With older versions of the da Vinci system, there were limitations with regard to accessibility to patients during intraoperative care. These concerns have been improved with the newer platforms which have improved access to the patient's airway and extremities even when the system is docked and in use. The improved access is considered a comparative safety benefit of the new system. Patients should be securely positioned and padded to prevent skin and soft tissue damage during the prolonged immobility required during the procedure. Robotic arms may contact the patient's head, body or extremities during surgical movements (Figure 4). The endotracheal tube and all intravenous catheters must be secured. Assurance that all non-invasive monitoring is placed and working is ensured prior to docking the robot. Adequate intravenous access is generally secured prior to the start of the procedure as patient access is somewhat limited intraoperatively due to the presence of the robotic and the placement of the patient's arms at their side. For prolonged procedures, a urinary catheter is placed. Use of a catheter with an indwelling temperature probe is helpful to allow intraoperative temperature monitoring. For intravenous infusions, free dripping devices are generally used for fluid administration as they may allow earlier detection of intravenous infiltrations. When infusion pumps are used for fluids or medications, the pressure limits should be checked regularly. More recently, new devices have entered the market that are suggested to allow for earlier detection of IV infiltrates when direct observation of the site is limited. ${ }^{38}$

Data from the adult literature demonstrate the importance of patient positioning and padding as information from adults has demonstrated that the most frequent complications have included peripheral neuropathies, corneal abrasions, vascular complications including compartment syndrome, and the effect of edema (cerebral, ocular and airway). ${ }^{39}$ The authors concluded that the combination of Trendelenburg position with insufflation and longer procedural times was highly related to the risks of complications; therefore, positioning must be appropriate for patients' safety. Pre-existing neurologic condition, obesity and procedure times greater than 240 minutes were the identified risk factors for complications.

Additionally, there may always be the need for conversion to an open surgical procedure for various reasons. In a retrospective review of 39 pediatric-aged patients, conversion to an open procedure was required in $3(7.5 \%)$ due to inadequate surgical working space. ${ }^{40}$ This was related to marked bowel distention in two patients and insufficient ability to provide hepatic retraction in one patient. These 3 patients were significantly younger (mean age of 2.97 versus 9.83 years) and weighed less (mean weight of 11.83 versus 35.47 kilograms) than the remainder of the surgical cohort. Other factors responsible for the need for conversion to an open procedure were not identified including duration of mask ventilation before endotracheal intubation, dose of neuromuscular blocking age, and the type of bowel preparation that had been used. The authors concluded that the incidence of conversion to an open procedure was acceptable and was mainly related to inadequate working space in smaller patients and not influenced by measurable anesthetic factors or different regimens for bowel preparation.

\section{Preoperative and Intraoperative Anesthetic Management}

Intraoperatively, standard American Society of Anesthesiologists' monitoring is recommended in otherwise healthy patients. Two peripheral intravenous catheters are generally placed as access to a patient is limited during a procedure. More invasive monitoring may be indicated based on the patient's comorbid conditions. An arterial line cannula may be beneficial for frequent blood monitoring, in a patient with cardiovascular or respiratory complications or for a procedure which has a potential for hemodynamic instability due to bleeding or interreference of large vessels. In our practice, a depth of anesthesia monitor may be useful to allow titration of anesthetic agents and prevent patient movement. There are several approaches for anesthetic induction and maintenance, including inhalation or intravenous techniques. To date, there is no evidence to demonstrate the superiority of any technique. 
As with traditional minimally invasive techniques, nitrous oxide is avoided for robotic procedures since it may cause bowel distension. In addition, the technique is chosen to limit the potential for postoperative nausea and vomiting as one of the goals of minimally invasive surgery is early ambulation and hospital discharge. Endotracheal intubation with a cuffed endotracheal tube is recommended to minimize an air leak during mechanical ventilation especially when IAP increases during $\mathrm{CO} 2$ insufflation. Neuromuscular blockade (NMBA) is required for RAS to avoid injury from unexpected patient movement, facilitate mechanical ventilation, and improve visualization of the surgical field. The fixed nature of the instrumentation when the robot is docked and instruments are inserted can result in serious organ or vascular injury if the depth of anesthesia is inadequate and there is patient movement. Given such concerns, neuromuscular blockade is continued throughout the procedure with appropriate monitoring to maintain the needed level of blockade.

Enhanced Recovery After Surgery (ERAS) techniques are widely used for robotic-assisted colorectal and gastrointestinal tract surgery. ${ }^{41,42}$ ERAS is a multimodal, multidisciplinary approach aimed to provide faster patient recovery from a surgical procedure. These guidelines include the administration of carbohydrate drinks up to 2 hours before surgery, minimally invasive surgery, specifics regarding intraoperative intravenous fluid management, avoidance of or early removal of drains and tubes, early ambulation and the initiation of oral intake the day of the procedure. These techniques have been successful in achieving improved recovery profiles, shorter length of hospital stay, reductions in postoperative complications, decreased readmission rates, and cost reduction. Although initially introduced in the adult population, similar successes have been reported in pediatric-aged patients. ${ }^{41}$ A single institution experience with the implementation of ERAS for pediatric colorectal surgery demonstrated a significant decrease in median hospital length of stay with no increase in complications or readmission rates. ${ }^{42}$ The ERAS protocol from our institution is summarized in Table 3.

\section{Postoperative Care Including Pain Management}

Like the traditional minimally invasive approach, RAS reduces the requirement for the administration of
Table 3 Modified ERAS Protocol for Robotic-Assisted Colorectal Surgery

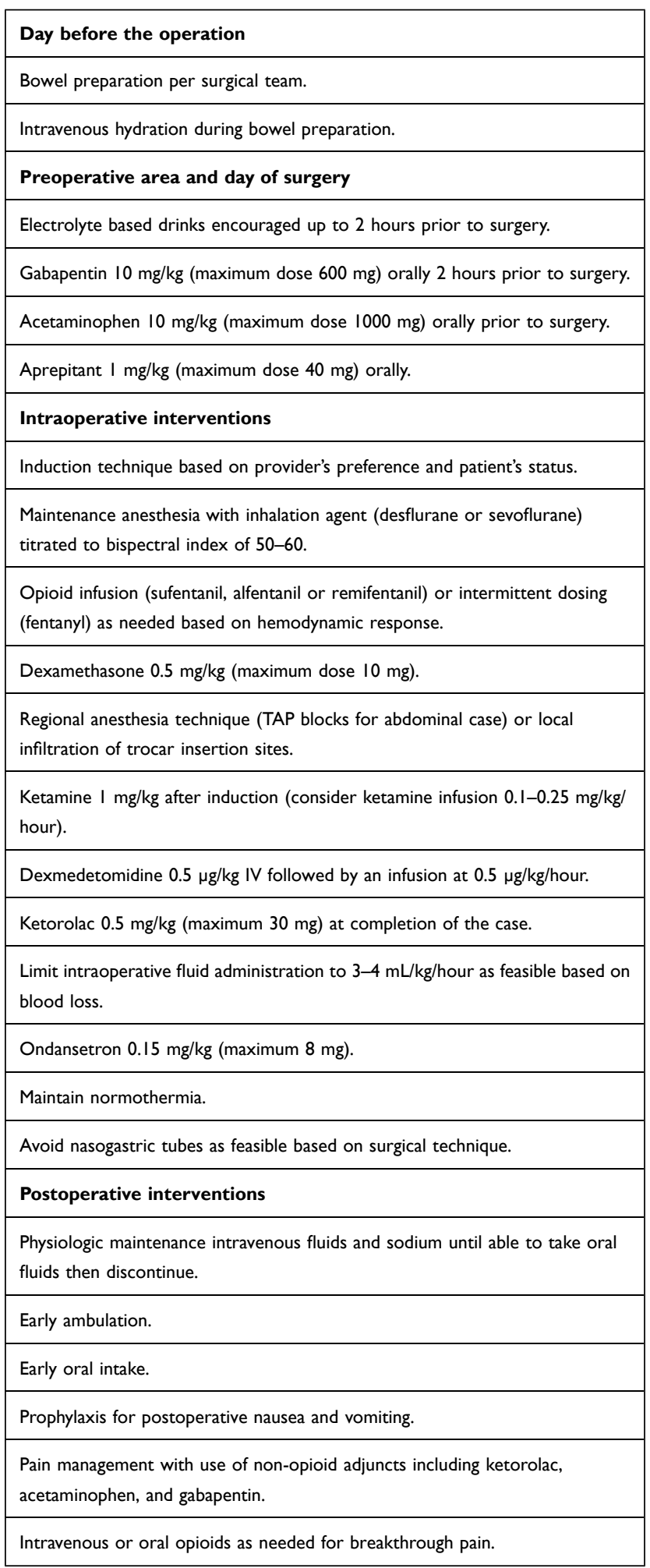

postoperative analgesics when compared with open surgical techniques and has been reported to have more favorable pain profiles when directed compared to non-robotic 
minimally invasive techniques. ${ }^{4-45}$ This less invasive approach, in combination with the use of ERAS protocols which emphasize adjunctive analgesic agents, has allowed for minimizing postoperative opioid utilization facilitating earlier ambulation and hospital discharge. Limitation of the need for parenteral opioids can also be facilitated by the use of regional anesthetic techniques and the parenteral administration of non-opioid agents such as acetaminophen and a non-steroidal anti-inflammatory agent. ${ }^{46}$ Regional anesthetic techniques may include transversus abdominis plane (TAP) blockade or infiltration of the access sites with a local anesthetic agent of the amide class (bupivacaine, levobupivacaine or ropivacaine). Total dosing of these agents should be limited to $2-2.5 \mathrm{mg} / \mathrm{kg}$ with the concentration adjusted from $0.2-0.5 \%$ according to the volume required to achieve satisfactory fascial spread and dermatome coverage. Opioids can be administered intravenously (morphine, hydromorphone) or orally (oxycodone) as needed for breakthrough pain.

\section{Conclusion}

Following successes and demonstrated advantages in the adult population, the applications of RAS will continue to expand among pediatric patients. ${ }^{47}$ Innovations in the equipment will make these techniques more suited for smaller patients. Despite the reported advantages of the technique, robotic surgery imposes specific challenges for the anesthesia provider especially in the pediatric-aged patient. In addition to our review, the reader is referred to reference 46 for more information regarding these concerns. ${ }^{48}$ Although recent innovations have improved access to the patient, even the modern generation of robotic surgical systems may limit the anesthesia providers' access to the patient thereby mandating careful preoperative assessment and planning. Intraoperative anesthetic concerns include the physiologic impact of $\mathrm{CO} 2$ insufflation and increased IAP, concerns that are shared by and similar for minimally invasive (laparoscopy and thoracoscopy) and robotic techniques. Given the fixed nature of the instruments and the operating console, a deep level of neuromuscular blockade is maintained during the procedure to avoid the potential for organ and vascular injury should inadvertent patient movement occur. As these techniques evolve, evidence-based medicine is needed to evaluate the cost-benefits of robotic surgery, its impact on postoperative outcomes (pain, length of hospital stay), and identify the optimal techniques for perioperative care including anesthetic regimens, ERAS techniques, and intraoperative monitoring.

\section{Disclosure}

Dr Michalsky has received an honorarium from Intuitive Surgical, Inc (Sunnyvale, CA) for professional educational services rendered. Intuitive Surgical, Inc has had no involvement or access to the original content reported in the work. None of the authors have a competing financial interest, and report no other conflicts of interest in this work.

\section{References}

1. Kostakis ID, Alexandrou A, Armeni E, et al. Comparison between minimally invasive and open gastrectomy for gastric cancer in Europe: a systematic review and meta-analysis. Scand J Surg. 2017;106:3-20. doi:10.1177/1457496916630654

2. Corrado G, Calagna G, Cutillo G, et al. The patient and observer scar assessment scale to evaluate the cosmetic outcomes of the robotic single-site hysterectomy in endometrial cancer. Int J Gynecol Cancer. 2018;28:194-199. doi:10.1097/IGC.0000000000001130

3. Darr C, Cheufou D, Weinreich G, Hachenberg T, Aigner C, Kampe S. Robotic thoracic surgery results in shorter hospital stay and lower postoperative pain compared to open thoracotomy: a matched pairs analysis. Surg Endosc. 2017;31:4126-4130. doi:10.1007/s00464-0175464-6

4. Ficarra V, Novara G, Artibani W, et al. Retropubic, laparoscopic and robot-assisted radical prostatectomy: a systematic review and cumulative analysis of comparative studies. Eur Urol. 2009;55:1037-1063. doi:10.1016/j.eururo.2009.01.036

5. Bijlani A, Hebert AE, Davitian M, et al. A multidimensional analysis of prostate surgery costs in the United States: robotic-assisted versus retropubic radical prostatectomy. Value Health. 2016;19:391-403. doi:10.1016/j.jval.2015.12.019

6. Tandogdu Z, Vale L, Fraser C, Ramsay C. A systematic review of economic evaluations of the use of robotic assisted laparoscopy in surgery compared with open or laparoscopic surgery. Appl Health Econ Health Policy. 2015;13:457-467. doi:10.1007/s40258-0150185-2

7. Molinaro F, Angotti R, Bindi E, et al. Low weight child: can it be considered a limit of robotic surgery? Experience of two centers. J Laparoendosc Adv Surg Tech A. 2019;29:698-702. doi:10.1089/ lap.2017.0681

8. Ellison J, Lendvay T. Robot-assisted ureteroureterostomy in pediatric patients: current perspectives. Robot Surg. 2017;4:45-55. doi:10.2147/RSRR.S99536

9. Ballouhey Q, Villemagne T, Cros J, et al. A comparison of robotic surgery in children weighing above and below $15.0 \mathrm{~kg}$ : size does not affect surgery success. Surg Endosc. 2015;29:2643-2650. doi:10.1007/s00464-014-3982-z

10. Tobias JD. Anesthetic considerations for laparoscopy in children. Sem Laparoscop Surg. 1998;5:60-66.

11. Gupta R, Singh S. Challenges in paediatric laparoscopic surgeries. Indian J Anaesth. 2009;53:560-566.

12. Wedgewood J, Doyle E. Anaesthesia and laparoscopic surgery in children. Paediatr Anaesth. 2001;11:391-399. doi:10.1046/j.14609592.2001.00519.x

13. Spinelli G, Vargas M, Aprea G, Cortese G, Servillo G. Pediatric anesthesia for minimally invasive surgery in pediatric urology. Transl Pediatr. 2016;5:214-221. doi:10.21037/tp.2016.09.02

14. Dion JM, McKee C, Tobias JD, et al. Ventilation during laparoscopic-assisted, bariatric surgery: volume-controlled, pressure-controlled or volume-guaranteed, pressure-regulated modes? Int J Clin Exp Med. 2014;7:2242. 
15. Dion JM, McKee C, Tobias JD, et al. Carbon dioxide monitoring during laparoscopic-assisted surgery in severely obese patients: transcutaneous versus end-tidal techniques. J Clin Monit Comput. 2015;29:183-186. doi:10.1007/s10877-014-9587-1

16. Joris JO, Noirot DP, Legrand MJ, Jacquet NJ, Lamy ML. Hemodynamic changes during laproscopic cholecystectomy. Anesth Analg. 1993;76:1067-1071. doi:10.1213/00000539-199305000-00027

17. Cunningham AJ, Turner J, Rosenbaum S, Rafferty $T$. Transesophageal echocardiographic assessment of haemodynamic function during laparoscopic cholecystectomy. $\mathrm{Br} J$ Anaesth. 1993;70:621-625. doi:10.1093/bja/70.6.621

18. Critchley LA, Critchley JA, Gin T. Haemodynamic changes in patients undergoing laparoscopic cholecystectomy: measurement by transthoracic electrical bioimpedance. $\mathrm{Br} J$ Anaesth. 1993;70:681-683. doi:10.1093/bja/70.6.681

19. O'Leary E, Hubbard K, Tormey W, Cunningham AJ. Laparoscopic cholecystectomy: haemodynamic and neuroendocrine responses after pneumoperitoneum and changes in position. $\mathrm{Br} J$ Anaesth. 1996;76:640-644. doi:10.1093/bja/76.5.640

20. Branche PE, Duperret SL, Sagnard PE, Boulez JL, Petit PL, Viale JP. Left ventricular loading modifications induced by pneumoperitoneum. Anesth Analg. 1998;86:482-487. doi:10.1213/ 00000539-199803000-00005

21. De Waal EE, Kalkman CJ. Haemodynamic changes during lowpressure carbon dioxide pneumoperitoneum in young children. Paediatr Anaesth. 2003;13:18-25. doi:10.1046/j.14609592.2003.00973.x

22. Sakka SG, Huettemann E, Petrat G, Meier-Hellmann A, Schier F, Reinhart K. Transesophageal echocardiographic assessment of haemodynamic changes during laparoscopic herniorrhaphy in small children. Br J Anaesth. 2000;84:330-334. doi:10.1093/oxfordjournals.bja.a013434

23. Gueugniaud PY, Abisseror M, Moussa M, et al. The hemodynamic effects of pneumoperitoneum during laparoscopic surgery in healthy infants: assessment by continuous esophageal aortic blood flow echo-Doppler. Anesth Analg. 1998;86:290-293. doi:10.1097/ 00000539-199802000-00012

24. Kardos A, Vereczkey G, Pirot L, Nyirady P, Mekler R. Use of impedance cardiography to monitor haemodynamic changes during laparoscopy in children. Paediatr Anaesth. 2001;11:175-179. doi:10.1046/j.1460-9592.2001.00639.x

25. Kim J, Sun Z, Englum BR, et al. Laparoscopy is safe in infants and neonates with congenital heart disease: a national study of 3684 patients. $J$ Laparoendosc Adv Surg Tech. 2016;26:836-839. doi:10.1089/lap.2016.0232

26. Anderberg M, Kockum CC, Arnbjornsson E. Morgagni hernia repair in a small child using da Vinci robotic instruments - a case report. Eur J Pediatr Surg. 2008;19:110-112. doi:10.1055/s-2008-1038500

27. Ballouhey Q, Villemagne T, Cros J, et al. Assessment of paediatric thoracic robotic surgery. Interact Cardiovasc Thorac Surg. 2014;20:300-303. doi:10.1093/icvts/ivu406

28. Obasi PC, Hebra A, Varela JC. Excision of esophageal duplication cysts with robotic-assisted thoracoscopic surgery. JSLS. 2011;15:244-247. doi:10.4293/108680811X13071180406961

29. Meehan JJ. Robotic surgery in small children: is there room for this? J Laparoendosc Adv Surg Tech A. 2009;19:707-712. doi:10.1089/ lap.2008.0178

30. Suematsu Y, Mora BN, Mihaljevic T, Nido PJ. Totally endoscopic robotic-assisted repair of patent ductus arteriosus and vascular ring in children. Ann Thorac Surg. 2005;80:2309-2313. doi:10.1016/j. athoracsur.2005.05.078
31. Tobias JD. Anesthesia for neonatal thoracic surgery. Best Pract Res. 2004;18:303-320.

32. Tobias JD. Anesthesia for thoracic surgery in children. Curr Opin Anesthesiol. 2001;14:77-85. doi:10.1097/00001503-20010200000013

33. Hammer GB. Single-lung ventilation in infants and children. Paediatr Anaesth. 2004;14:98-102. doi:10.1046/j.14609592.2003.01197.x

34. Gallego-Poveda J, Guerra NC, Carvalheiro C, et al. Use of $\mathrm{CO}_{2}$ in video assisted thoracic surgery and single-lumen endotracheal tubea new less invasive approach. J Thorac Dis. 2017;9(4):903-906. doi:10.21037/jtd.2017.01.53

35. Tran DT, Badner NH, Nicolaou G, Sischek W. Arterial pCO2 changes during thoracoscopic surgery with $\mathrm{CO}_{2}$ insufflation and one lung ventilation. HSR Proc Intensive Care Cardiovasc Anesth. 2010;2:191-197.

36. Kalfa N, Allal H, Raux O, et al. Tolerance of laparoscopy and thoracoscopy in neonates. Pediatrics. 2005;116:e785-e791. doi: $10.1542 /$ peds.2005-0650

37. Kumar K, Basker S, Jeslin L, Karthikeyan C, Matthias A. Anaesthesia for pediatric video assisted thoracoscopic surgery. J Anaesthesiol Clin Pharmacol. 2011;27:12-16.

38. Doellman D, Rineair S, Johnson N, Rineair S, Johnson N. The use of optical detection for continuous monitoring of pediatric IV sites. J Assoc Vasc Access. 2019;24:44-47. doi:10.2309/j. java.2019.002.003

39. Ashrafian H, Clancy O, Grover V, Darzi A. The evolution of robotic surgery: surgical and anaesthetic aspects. Br J Anaesth. 2017;119: i72-i84. doi:10.1093/bja/aex383

40. Di Fabrizio D, Lisi G, Lauriti G, et al. Conversion rate in pediatric robotic-assisted surgery: looking for the culprit. J Laparoendosc Adv Surg Tech A. 2020;30:315-321. doi:10.1089/lap.2019.0653

41. Reismann M, Dingemann J, Wolters M, Laupichler B, Suempelmann R, Ure BM. Fast-track concepts in routine pediatric surgery: a prospective study in 436 infants and children. Langenbecks Arch Surg. 2008;394:529-533. doi:10.1007/s00423-008-0440-1

42. Short HL, Heiss KF, Burch K, et al. Implementation of an enhanced recovery protocol in pediatric colorectal surgery. J Pediatr Surg. 2018;53:688-692. doi:10.1016/j.jpedsurg.2017.05.004

43. Bansal D, Cost NG, DeFoor WR, et al. Infant robotic pyeloplasty: comparison with an open cohort. J Pediatr Urol. 2014;10:380-385. doi:10.1016/j.jpurol.2013.10.016

44. Ballouhey Q, Binet A, Clermidi P, et al. Partial nephrectomy for small children: robot-assisted versus open surgery. Int $J$ Urol. 2017;24:855-860. doi:10.1111/iju.13466

45. Molinaro F, Krasniqi P, Scolletta S, et al. Considerations regarding pain management and anesthesiological aspects in pediatric patients undergoing minimally invasive surgery: robotic vs laparoscopic-thoracoscopic approach. $J$ Robot Surg. 2020;14:423-430. doi:10.1007/s11701-019-01005-1

46. Faasse MA, Lindgren BW, Frainey BT, et al. Perioperative effects of caudal and transversus abdominis plane (TAP) blocks for children undergoing urologic robot-assisted laparoscopic surgery. J Pediatr Urol. 2015;11:e1-e7. doi:10.1016/j.jpurol.2014.10.010

47. Spinoit AF, Nguyen H, Subramaniam R. Role of robotics in children: a brave new world! Eur Urol Focus. 2017;3:172-180. doi:10.1016/j. euf.2017.08.011

48. Mishra P, Gupta B, Nath A. Anesthetic considerations and goals in robotic pediatric surgery: a narrative review. $J$ Anesth. 2020;34:286-293. doi:10.1007/s00540-020-02738-2 


\section{Publish your work in this journal}

Robotic Surgery: Research and Reviews is an international, peer reviewed, open access, online journal publishing original research, commentaries, reports, and reviews on the theory, use and application of robotics in surgical interventions. Articles on the use of supervisorycontrolled robotic systems, telesurgical devices, and shared-control systems are invited. The manuscript management system is completely online and includes a very quick and fair peer review system, which is all easy to use. Visit http://www.dovepress.com/testimonials. php to read real quotes from published authors.

Submit your manuscript here: https://www.dovepress.com/robotic-surgery-research-and-reviews-journal 